\title{
Mutations acquired by hepatocellular carcinoma recurrence give rise to an aggressive phenotype
}

\author{
Ji-Hye Choi ${ }^{1,2, *}$, Min Jae Kim ${ }^{1,2, *}$, Yong Keun Park ${ }^{4}$, Jong-Yeop Im ${ }^{1,2}$, So Mee Kwon ${ }^{1,2}$, \\ Hyung Chul Kim ${ }^{3}$, Hyun Goo Woo ${ }^{1,2}$, Hee-Jung Wang ${ }^{5}$ \\ ${ }^{1}$ Department of Physiology, Ajou University School of Medicine, Suwon, Korea \\ ${ }^{2}$ Department of Biomedical Science, Graduate School, Ajou University, Suwon, Korea \\ ${ }^{3}$ Developmental Therapeutics Branch, Center for Cancer Research, National Cancer Institute, National Institutes of Health, \\ Bethesda, Maryland, United States \\ ${ }^{4}$ Department of Surgery, Catholic Kwandong University International St. Mary's Hospital, Incheon, Korea \\ ${ }^{5}$ Department of Surgery, Ajou University School of Medicine, Suwon, Korea \\ "These authors have contributed equally to this work \\ Correspondence to: Hyun Goo Woo, email: hg@ajou.ac.kr \\ Hee-Jung Wang, email: wanghj@ajou.ac.kr
}

Keywords: RNA-Seq, GOLGB1, SF3B3, recurrence, mutation

Received: September 09,2016_Accepted: December 01,2016Ｐublished: December 27, 2016

\section{ABSTRACT}

Recurrence of hepatocellular carcinoma (HCC) even after curative resection causes dismal outcomes of patients. Here, to delineate the driver events of genomic and transcription alteration during HCC recurrence, we performed RNA-Seq profiling of the paired primary and recurrent tumors from two patients with intrahepatic HCC. By comparing the mutational and transcriptomic profiles, we identified somatic mutations acquired by HCC recurrence including novel mutants of GOLGB1 (E2721V) and SF3B3 (H804Y). By performing experimental evaluation using siRNA-mediated knockdown and overexpression constructs, we demonstrated that the mutants of GOLGB1 and SF3B3 can promote cell proliferation, colony formation, migration, and invasion of liver cancer cells. Transcriptome analysis also revealed that the recurrent HCCs reprogram their transcriptomes to acquire aggressive phenotypes. Network analysis revealed CXCL8 (IL-8) and SOX4 as common downstream targets of the mutants. In conclusion, we suggest that the mutations of GOLGB1 and SF3B3 are potential key drivers for the acquisition of an aggressive phenotype in recurrent HCC.

\section{INTRODUCTION}

Hepatocellular carcinoma (HCC) is the fifth most malignant cancer and the second leading cause of cancer death in the world [1]. Currently, definitive treatment of HCC is surgical resection and liver transplantation [2]. However, tumor recurrence even after curative surgical resection occurs at a rate of $40 \%$ cases within 5 years, resulting in dismal outcomes of HCC patients [3]. Recurrent tumors have been addressed to harbor distinct genomic profiles compared to primary tumors, suggesting an intracellular reprogramming during tumor recurrence. Indeed, recurrent tumors acquire aggressive phenotypes such as invasion, metastasis, epithelial-to-mesenchymal transition (EMT), and chemo-resistance properties, provoking worse prognostic outcomes of tumor patients [4-8]. Therefore, delineating the underlying mechanisms of $\mathrm{HCC}$ recurrence are urgently needed to improve clinical outcomes of HCC patients.

Recent explorative advance of high-throughput sequencing technology has allowed us to get overviewed landscapes of genomic variations in cancers, which have revealed genetic drivers that might play critical roles in cancer progression. In HCC, several studies have shown recurrent mutations at TP53, CTNNB1, AXIN1, IRF2, CDKN1A, CDKN2A, ARID1A, ARID2, and TERT, which have been addressed to promote HCC development and/or progression implicating clinical outcomes [9-14]. Recurrent tumors showed distinct mutational and/or transcriptomic profiles compared to 
those of primary tumors [15-17]. These studies imply that the tumor relapse could be derived from the genetic events causing transcriptomic reprogramming of tumor cells. For example, phylogenetic analysis has shown a clonal evolution of the heterogeneous cancer cells with specific mutations can give rise to metastatic or aggressive tumors [18]. Thus, comparison of the genomic and/ or transcriptome profiles of the recurrent or metastatic tumors with primary tumors from the same patient might be advantageous in delineating the drivers for recurrent tumor progression.

With this concern, in the present study, we performed an RNA-Seq profiling in the paired primary and recurrent tumors from two patients with intrahepatic HCC (Patient 1 and Patient 2). By comparing the mutation profiles, we identified seven mutations which were found in the recurrent HCCs but not in the primary tumors from the same patients. Of these, we demonstrated that the novel mutants of $G O L G B 1$ and $S F 3 B 3$ can promote $\mathrm{HCC}$ progression, providing new mechanistic insights on the HCC relapse.

\section{RESULTS}

\section{Profiling of RNA-Seq identifies the mutants acquired by recurrence of $\mathrm{HCC}$}

RNA-Seq profiling was performed on the paired intrahepatic primary and recurred tumor specimens from two HCC patients as described in Materials and Methods. The patient 1 had 98 mutations in the primary tumor (P1) and 85 mutations in the recurrent tumor (R1). The patient 1 had 41 recur-specific mutations showing lower mutation retention rate $(31.65 \%)$. While, the patient 2 had 76 mutations in the primary tumor (P2) and 78 mutations in the recurrent tumor (R2), respectively. The R2 tumor showed higher mutation retention rate $(71.11 \%)$, having 14 newly acquired recur-specific mutations (Figure 1A). Each tumor had similar mutational spectrum in consistent with previous studies $[9,12]$. No significant difference of the mutation spectrum was found between the primary and the recurrent tumors (Figure 1B). Overall, the tumors had frequent mutations of $\mathrm{C}>\mathrm{T} / \mathrm{G}>\mathrm{A}(38.79 \%, \mathrm{n}=64)$ and $\mathrm{T}>\mathrm{C} / \mathrm{A}>\mathrm{G}(22.42 \%, \mathrm{n}=37)$ (Figure 1B, left). The ratios of nonsynonymous $v s$. synonymous SNVs were ranged from 2.1 to 2.71 (Figure 1B, right).

Among the mutations acquired by $\mathrm{HCC}$ recurrence (R1; $\mathrm{n}=41, \mathrm{R} 2 ; \mathrm{n}=14)$, we identified 9 recur-specific mutations which were commonly found in the recurrent tumors but not in the primary and the non-tumoral surrounding tissues. These recur-specific mutations were verified by Sanger sequencing method, but $V H L$ (E148fs) and BAAT (R297H) were failed to validate. The validated seven recur-specific mutations resided at the genes of TP53 (P278R), CCNL2 (R499R), ARID1A (G2012D), GOLGB1 (E2721V), EXOC3 (V202I), SF3B3
(H804Y), and C18orf32 (K75K) (Figure 1C and Table 1). These mutants included previously well-known cancerassociated genes such as TP53, CCNL2, and ARIDIA, implying their functional relevance in the HCC recurrence.

\section{Transcriptomic reprogramming of the recurrent $\mathrm{HCC}$}

Next, to delineate concomitant transcriptomic change during $\mathrm{HCC}$ relapse, we compared the gene expression levels of the primary and the recurrent HCCs with fold difference greater than two, which revealed 130 differentially expressed genes as the reprogrammed expression by recurrence (RER) including 60 up-regulated (RER_UP) and 70 down-regulated (RER_DOWN) genes (Figure 2A and Supplementary Table 1). Gene ontology (GO) analysis revealed that the RER_UP genes were enriched with the genes related with migration (enrichment scores, $\mathrm{ES}=4.12)$ and inflammatory response $(\mathrm{ES}=3.10)$, while RER_DOWN genes were enriched with metabolic process-related genes ( $\mathrm{ES}=7.12)$ (Figure $2 \mathrm{~B})$. This result indicates that the RER genes reflected well the aggressive phenotype of the recurrent $\mathrm{HCC}$, implying their regulatory functions on transcriptomic reprogramming during tumor relapse.

To further support the aggressive behavior of the recurrent $\mathrm{HCC}$, we evaluated the expression of the oncogenic signatures from the RNA-seq profile. As expected, the recurrent HCCs demonstrated significant enrichment of oncogenic signatures (e.g., EGFR and MEK) compared to those in the primary HCCs (Figure 2C). Down-regulation of tumor suppressive gene signatures such as TP53_DN.V1_UP, RPS14_DN.V1_UP, and MEL18 DN.V1 UP was observed in the recurrent HCCs. Moreover, consistent with these findings, the recurrent HCCs were enriched with the gene sets which were previously known to associate with cancer aggressiveness, including the gene sets of cell cycling, stemness (ES1, nanog, sox2, oct4, NOS, myc1, and myc2), and EMTrelated genes.

In addition, we also evaluated the prognostic relevance of the RER genes in an independent HCC data from TCGA (http://cancergenome.nih.gov). The HCC patients $(n=371)$ were stratified into two groups based on the enrichment scores (ES) of the RER genes which were calculated as described in Materials and Methods. The group with higher RER expression (RER high, ES $>0, n=100)$ showed worse prognostic outcomes of overall survival (Hazard ratio $\mathrm{HR}=2.07, P=9.01 \times 10^{-5}$ ) and tumor recurrence-free survival $\left(\mathrm{HR}=1.87, P=2.16 \times 10^{-4}\right)$ compared to those of the groups with lower RER expression (RER_low, ES $<0, \mathrm{n}=271$ ) (Figure 2D). Furthermore, we compared our RER gene signature with the previously reported HCC recurrence-related genes [6-8], but no significant overlap was found among these signatures. This might be due to different use of study 
design and data platforms. However, the recurrence genes in the previous study i.e. Woo et al. [6] had 15 genes overlapped with RER genes, which included many of the well-known representative markers of HCC recurrence such as CD24 [19], TGFB1 [20], CXCL6 [21], CXCL8 [22], and $P K M$ [23] (Figure 2E). These results consistently support that the recurrent HCCs presented more aggressive phenotype at transcriptional level, promoting genomic reprogramming during $\mathrm{HCC}$ relapse although limited sample size was used in this study.
The mutants of $G O L G B 1$ and $S F 3 B 3$ give rise to an aggressive phenotype

Ascertaining the aggressive phenotype of the recurrent HCCs, we next evaluated whether the mutants acquired by recurrence are responsible for the acquisition of the aggressive phenotype in the recurrent HCCs. First, we examined whether the mutationsacquired by recurrence can affect the expression levels of the genes. The expression of the 45 recur-specific
A

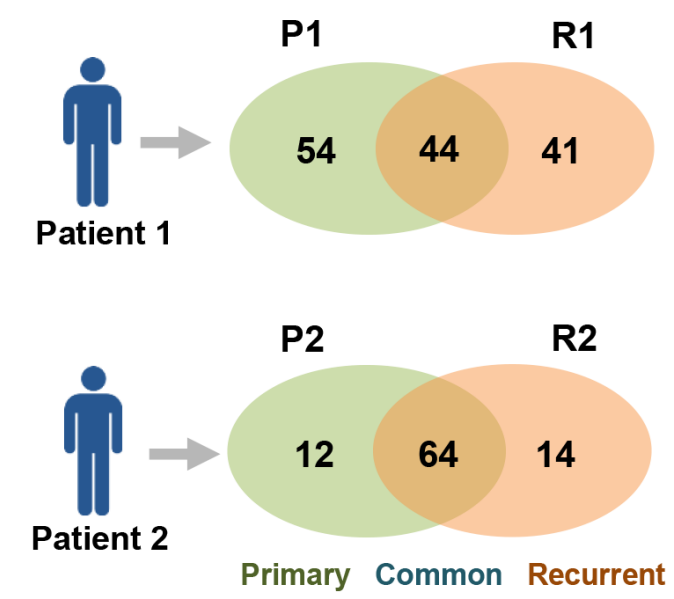

C

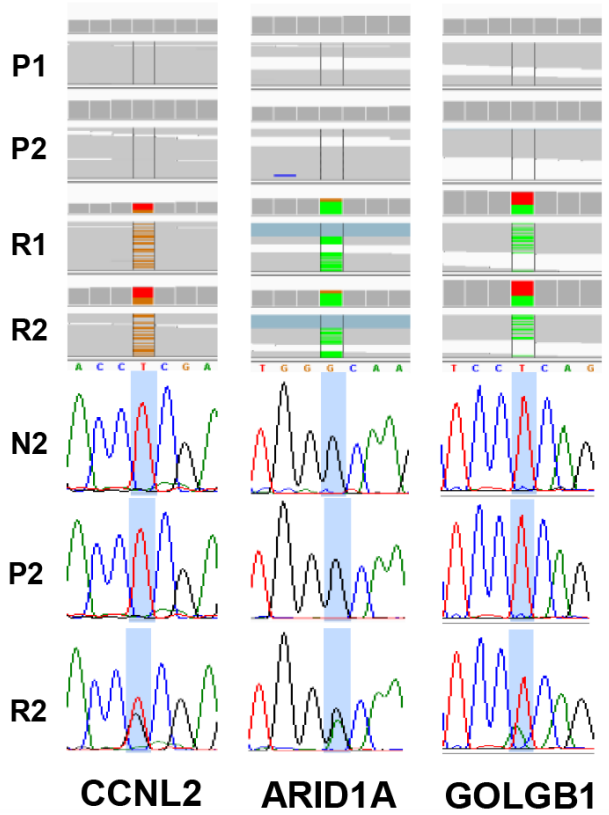

B
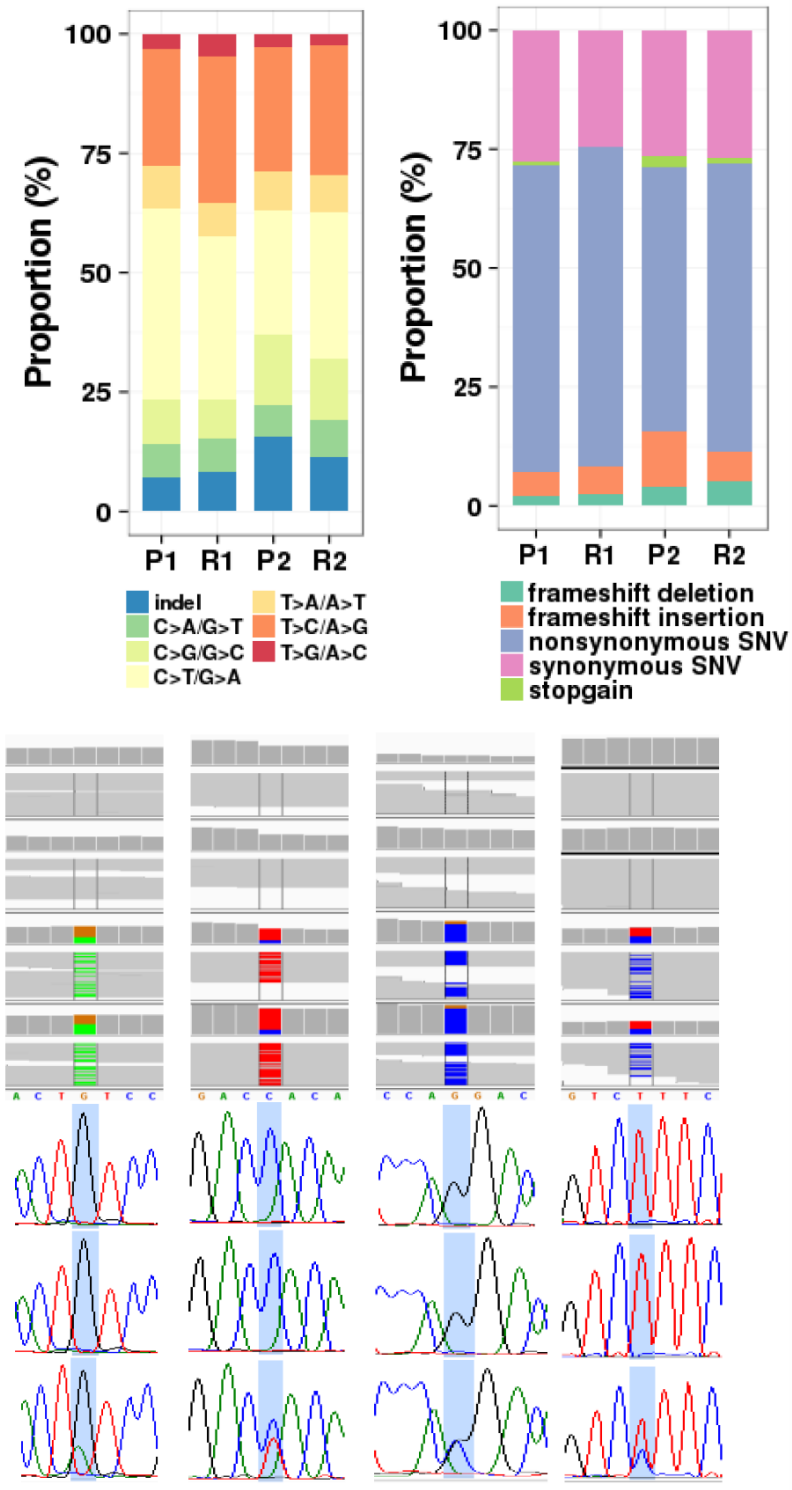

EXOC3

\section{TP53 C18orf32}

Figure 1: Identification of the mutants-acquired by HCC recurrence. A. A Venn-diagram shows the number of mutants found in the primary (P1 and P2) and recurrent tumors (R1 and R2) from each of patient 1 and patient 2. B. Distribution of the mutation types according to substitution types (left) and protein functions (right) in each HCC sample is shown. C. Assembled sequence leads with mutations are shown by Integrated Genome Viewer (IGV). The seven mutations of common recur-specific mutations were validated by Sanger sequencing method in each of the non-tumoral (N2), primary (P2), and recurrent tumor (R2) tissues from patient 2. 
Table 1: List of mutations-acquired by $\mathrm{HCC}$ recurrence

\begin{tabular}{|c|c|c|c|c|c|}
\hline Genome position & Cytoband & Mutation & Gene & $\begin{array}{l}\text { Amino Acid } \\
\text { change }\end{array}$ & $\begin{array}{c}\text { PolyPhen2 } \\
\text { score }\end{array}$ \\
\hline Chr1:1322679 & $1 \mathrm{p} 36.33$ & $\mathrm{~T}>\mathrm{G}$ & CCNL2 & R499R & . \\
\hline Chr1:27106424 & $1 \mathrm{p} 36.11$ & $\mathrm{G}>\mathrm{A}$ & ARID1A & G2012D & $\mathrm{D}($ score $=1)$ \\
\hline Chr3:121409809 & $3 q 13.33$ & $\mathrm{~T}>\mathrm{A}$ & GOLGB1 & E2721V & $\mathrm{D}($ score $=1)$ \\
\hline Chr5:453724 & $5 p 15.33$ & $\mathrm{G}>\mathrm{A}$ & EXOC3 & V202I & $\mathrm{P}(\mathrm{score}=0.88)$ \\
\hline Chr16:70597900 & $16 \mathrm{q} 22.1$ & $\mathrm{C}>\mathrm{T}$ & SF3B3 & H804Y & $\mathrm{D}($ score $=0.989)$ \\
\hline Chr17:7577105 & $17 \mathrm{p} 13.1$ & $\mathrm{G}>\mathrm{C}$ & TP53 & P278R & $\mathrm{D}($ score $=1)$ \\
\hline Chr18:47008721 & $18 \mathrm{q} 21.1$ & $\mathrm{~T}>\mathrm{C}$ & C18orf32 & $\mathrm{K} 75 \mathrm{~K}$ & . \\
\hline
\end{tabular}

* D: Probably damaging (score $>=0.957), \mathrm{P}$ : possibly damaging $(0.453<=$ score $<=0.956)$

mutated genes was significantly enriched in the recurrent $\mathrm{HCCs}$ than the primary $\mathrm{HCCs}(\mathrm{ES}=0.46, \mathrm{P}$-value $=0.03$, Figure $3 \mathrm{~A}-3 \mathrm{~B})$. However, the other mutants excluding the recur-specific mutations showed no significant directional changes of their expression levels between the primary and recurrent HCCs (Supplementary Figure 1). This result may imply that the recur-specific mutations are more likely to act as activating mutations causing overexpression of the mutated genes, although the other mutations might be either activating or inactivating mutations.

Next, to validate the likelihood of activating mutations of the recur-specific mutations, we performed siRNA-mediated knockdown experiments using liver cancer cell lines. Of the seven validated recur-specific mutations (Figure 1B), we focused on the newly identified missense mutants of GOLGB1 (H804Y) and SF3B3 (E2721V) because they were predicted to have deleterious structural alterations with Polyphen2 Scores greater than 0.9 (Table 1). Moreover, the functional roles of these genes in HCC progression are largely unknown yet. Indeed, GOLGB1 mutation was frequently observed in lung cancers $(9 \%)$, while the $S F 3 B 3$ mutation was frequently observed in bladder cancer (5.4\%) (Supplementary Figure 2). In $\mathrm{HCC}$, the mutations showed relatively lower frequencies ( $G O L G B 1,2.7 \% ; S F 3 B 3,1.9 \%$ ).

The siRNA-mediated knockdown of $G O L G B 1$ and $S F 3 B 3$ at transcriptional and protein levels were confirmed by quantitative RT-PCR and western blotting analyses, respectively (Supplementary Figure 3). Both the knockdown cells for $G O L G B 1$ or $S F 3 B 3$ suppressed cell proliferation activity in diverse liver cancer cell lines of HepG2, Huh7, Hep3B, SNU423, and PLC (Figure 3C). Moreover, we also demonstrated that the knockdown of these genes significantly reduced the migration activity of HepG2 cells, indicating their increased metastatic potential (Figure 3D).

In addition, to evaluate oncogenic functions of the mutants of $G O L G B 1$ and $S F 3 B 3$, wild-type and mutanttype clones were constructed by performing site-directed mutagenesis experiments. The expression clones were transfected into the liver cancer cells (HepG2 and Huh7), and the overexpression of each form was confirmed at mRNA and protein levels (Supplementary Figure 4). The expression of the wild-type $G O L G B 1$ or $S F 3 B 3$ significantly increased the cell proliferation as well as colony formation ability, respectively. Moreover, the mutant-type forms showed augmenting effects of the wildtype forms, promoting more aggressive cancer phenotypes of cell proliferation, colony formation, migration, and invasion, respectively (Figure 4). These results may indicate that the mutants act as activating mutations. The expression levels of the mutants were not much different between the primary and recurrent HCCs, indicating the mutation effects are not by elevation of the gene expression levels (Supplementary Figure 4).

The protein structures of the mutants were predicted to have deleterious functional effects by PolyPhen2 software (see Table 1). The mutation of GOLGB1 (E2721V) was located at a hinged region between $\alpha$-helix modules, and was predicted to alter the rotation angle of the hinge region (Figure 5A). The mutation of $S F 3 B 3$ (H804Y) was located at the boundary of $\beta$-sheet and loop structure, and was predicted to alter its loop structure of the wild-type into $\beta$-sheet (i.e. 805-807 and 813-815 sites) and $\alpha$-helix (i.e. $820-823$ sites) structures (Figure $5 \mathrm{~B})$. These results support that the mutations may lead to conformational change of proteins structures, promoting aggressive behaviors of cancer cells.

\section{CXCL8 and SOX4 are potential common downstream targets of $G O L G B 1$ and $S F 3 B 3$}

As we demonstrated that the mutations at $G O L G B 1$ and $S F 3 B 3$ can give rise to an aggressive progression in HCC (see Figure 3 and Figure 4), we next sought their potential downstream target genes which might be responsible for the phenotypic alteration by the mutations. By performing gene expression profiling using the knockdown cells for $G O L G B 1$ or $S F 3 B 3$, we identified 


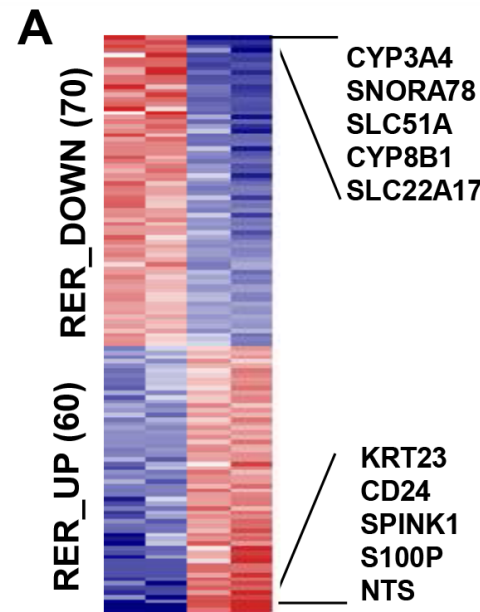

ธ ฐ 또 우

B

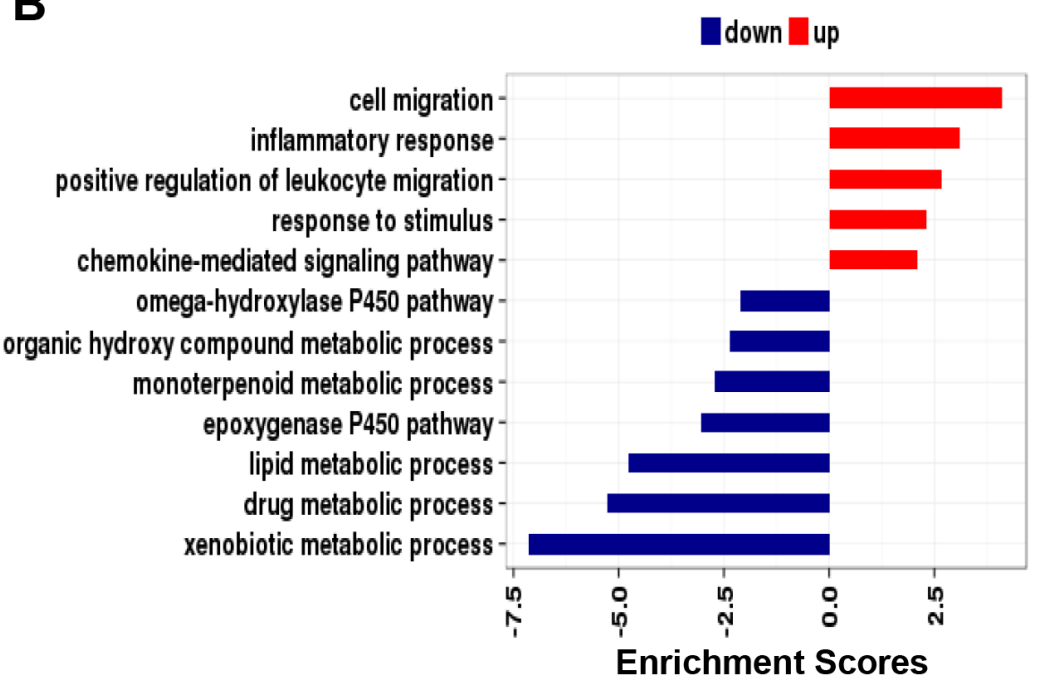

C

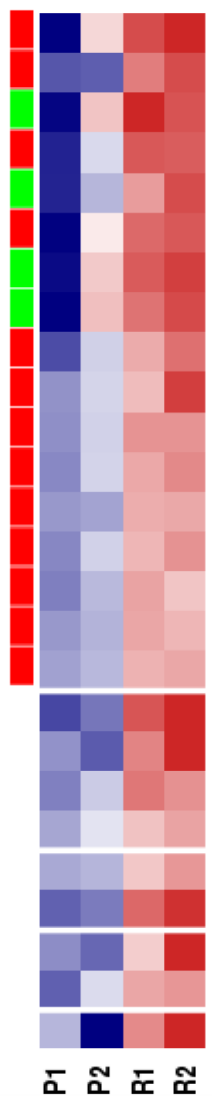
ธำ 또 뚜
EGFR UP.V1 UP MEK_UP.V1_UP STK33_NOMO_UP CAMP_UP.V1_DN VEGF_A_UP.V1_DN RPS14_DN.V1_UP STK33_SKM_UP STK33 UP MEL18_DN.V1_UP GCNP_SHH_UP_LATE.V1_UP BMI1_DN_MEL18_DN.V1_UP ESC_V6.5_UP_EARLY.V1_DN ERB2_UP.V1_UP SNF5_DN.V1_UP LTE2_UP.V1_UP BMI1_DN.V1_UP P53_DN.V1_UP nanog

sox2

oct 4

NOS

myc1

myc2

ES1

EMT_UP Cycling

\section{TCGA LIHC}
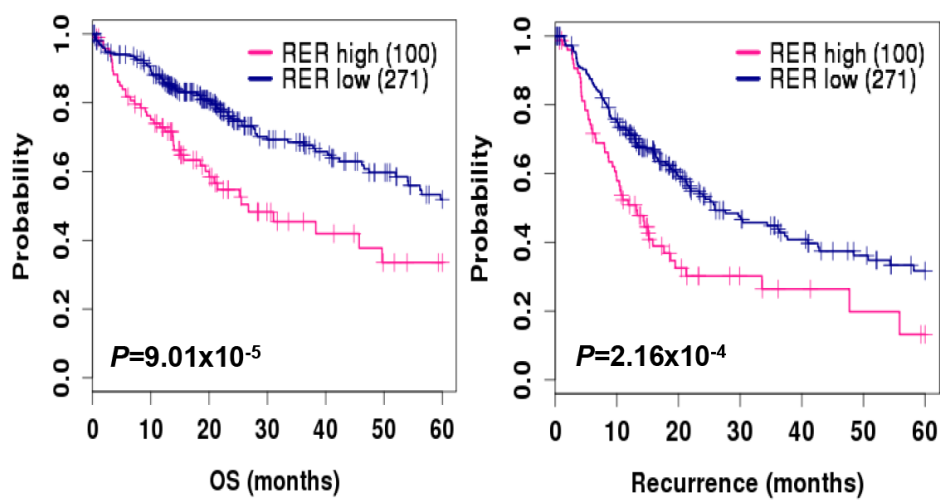

E

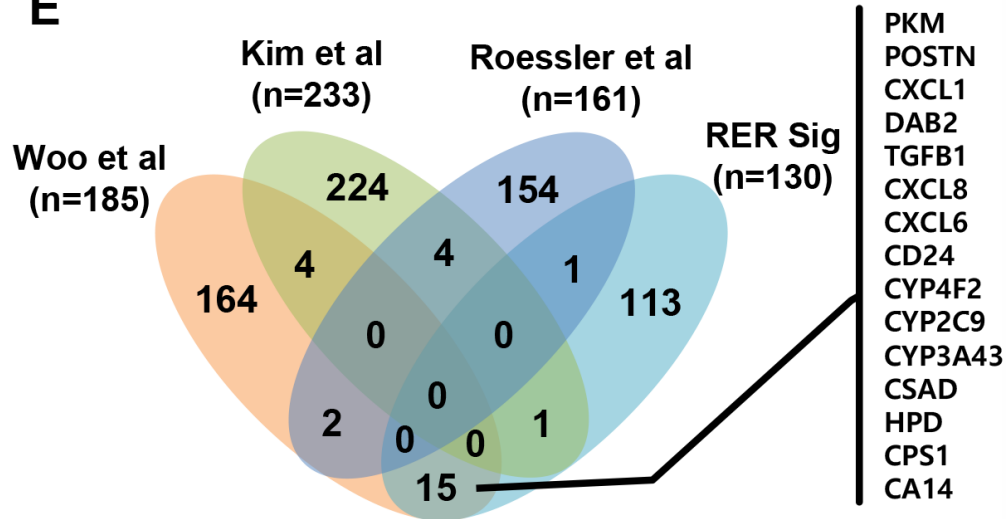

Figure 2: Differential expression between primary and recurrent HCC. A. A heatmap shows the expression of the gene set of "reprogrammed expression by recurrence (RER)" which are differentially up- and down-regulated genes between the primary and the recurrent HCCs. Top 10-ranked genes with the greatest fold differences are indicated. B. A barplot indicates the functional enrichment scores of RER_UP ( $\mathrm{n}=60$, red $)$ and RER_DOWN ( $=70$, blue) genes which are calculated as described in Materials and Methods. C. A heatmap indicates the enrichment scores of the cancer-related gene signatures including the oncogenic features from MsigDB, stemness (ES1, nanog, sox2, oct4, NOS, myc1, and myc2), EMT_UP, and cell cycling in each of HCC samples. The oncogenic (red) and tumor suppressive (green) features of MSigDB are indicated as a color bar (left). D. Kaplan-Meier survival curves show the overall survival (left) and recurrence-free survival (right) between RER_high and RER_low groups in TCGA cohort. E. A Venn-diagram shows the number of genes overlapped among the RER_UP genes and the recurrence-related gene signatures from the previous studies of Woo et al., Kim et al., and Rossler et al., respectively. 
the differentially expressed genes (DEG) for $G O L G B 1$ knockdown (i.e. siGOLGB1_UP, n=11, and siGOLGB1 DOWN, $\mathrm{n}=126$ ) and for $S F 3 \bar{B} 3$ knockdown (i.e. siSF3B3 UP, $n=21$, and siSF3B3_DOWN, $n=53$ ), respectively (Figure 6A and Supplementary Table 2). Since the downregulated genes by the knockdown are thought as their downstream target genes, we evaluated the expression of the siGOLB1_DOWN and siSF3B3_DOWN gene signatures. As expected, we found that the each of the siGOLB1_DOWN and siSF3B3_DOWN gene signatures was significantly enriched in the recurrent HCCs than the primary HCCs (Figure 6B). Individual enrichment scores of these gene signatures also showed marked upregulation in the recurrent tumors ( $\mathrm{R} 1$ and $\mathrm{R} 2$ ) compared to the primary tumors (P1 and P2) (Figure 6C). Taken together, we suggest that the genes regulated by GOLGB1

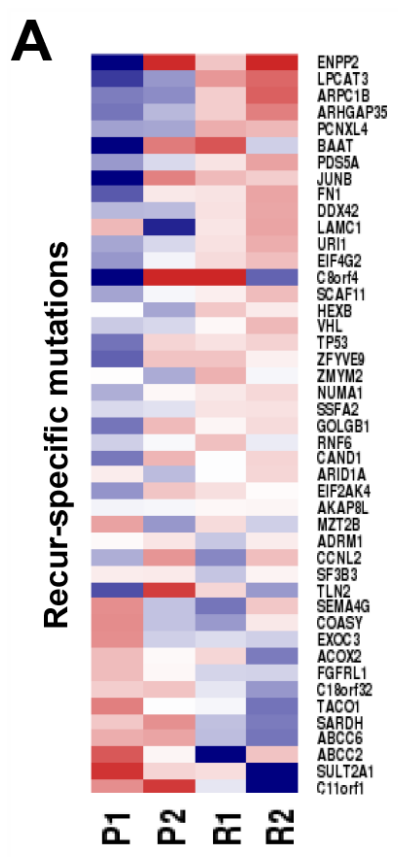

B
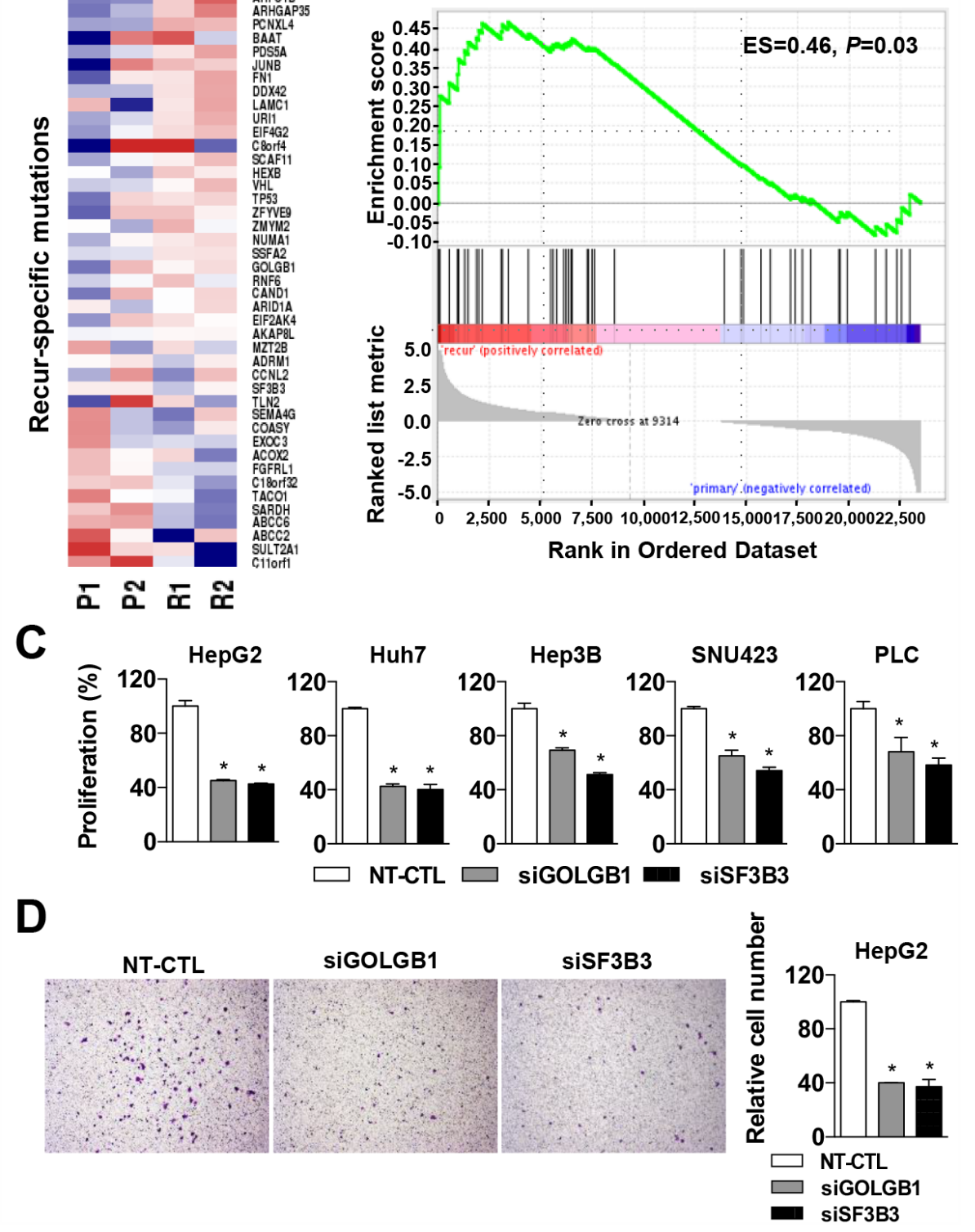

Figure 3: Functional evaluation of the recur-specific mutations. A. A heatmap indicates the expression levels of recur-specific mutant genes in HCC samples. B. Gene set enrichment analysis shows the enriched expression of the recur-specific mutant genes in recurrent HCC compared to those of the primary HCCs. C. Effects of the siRNA-mediated knockdown of NT-CTL (non-target control), GOLGB1 or SF3B3 for $72 \mathrm{hrs}$ on the cell proliferation are shown in liver cancer cells of HepG2, Huh7, Hep3B, SNU423 and PLC. The cell proliferation activities are determined by a MTT assay. D. Cell migration was determined using the Transwell chamber with the cells transfected with siRNAs for NT-CTL (non-target control), GOLGB1, and SF3B3, respectively. The number of migrated cells for each cell group is quantitated. Data are the mean \pm S.D. $(n=3) . * P<0.05$ with respective control. 
or $S F 3 B 3$ may act as potential downstream effector genes, playing crucial roles in the acquisition of the aggressive phenotype in the recurrent HCCs.

As the sigOLGB1_DOWN and siSF3B3 DOWN signatures are thought as potential targets regulated by $G O L G B 1$ or $S F 3 B 3$, we next proceeded a network analysis to predict key regulators of the gene expression changes. We constructed gene networks of the siGOLGB1_DOWN, siSF3B3_DOWN, and RER_UP gene signatures, respectively (Figure 6D).
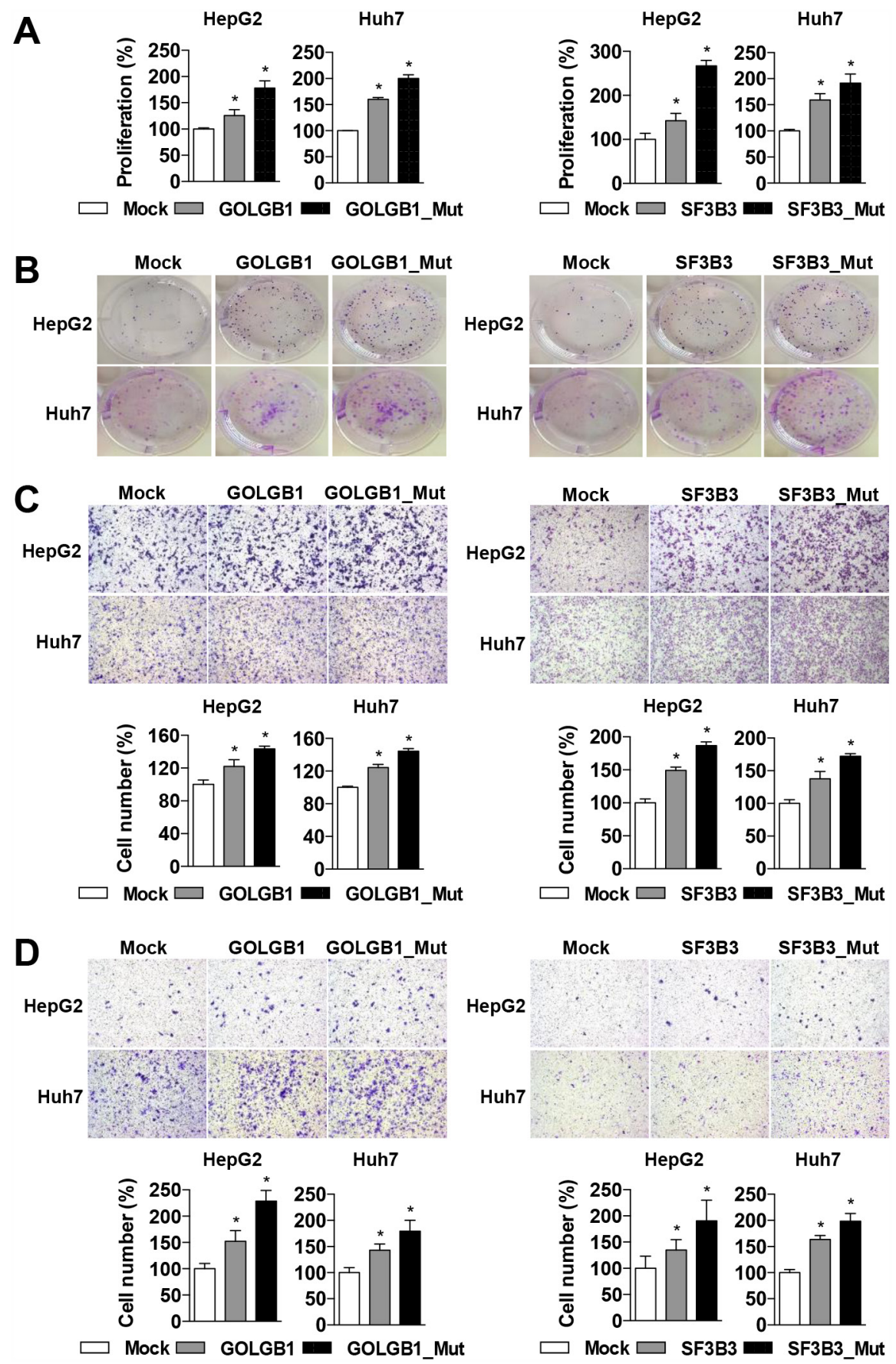

Figure 4: GOLGB1 and $S F 3 B 3$ mutants give rise to aggressive phenotypes. A. HepG2 and Huh7 Cells are transfected with mock control, wild-type, or mutant-type of GOLGB1 or $S F 3 B 3$ for $72 \mathrm{hrs,} \mathrm{respectively,} \mathrm{and} \mathrm{their} \mathrm{effects} \mathrm{on} \mathrm{cell} \mathrm{proliferation} \mathrm{are} \mathrm{determined}$ by a MTT assay. B. Colony formation assays are performed on the cells transfected with mock, wild-type, or mutant-type of $G O L G B 1$ or $S F 3 B 3$ for 14 days, respectively. C, D. The HepG2 and Huh7 cells transfected with mock, wild-type, or mutant-type of GOLGB1 or SF3B3, and their effects on cell migration (C) and invasion (D) activities are determined as described in Materials and Methods. The number of migrated or invaded cells is counted and plotted, respectively. Data are the mean \pm S.D. $(n=3) . * P<0.05$ with respective control. 
The genetic, physical, and pathway interactions among the signature were identified by GeneMANIA software [24]. Both the gene signatures of siGOLGB1_DOWN and siSF3B3_DOWN shared many genes $(25.17 \%, 36$ out of 143) each other, implying that the concomitant mutations might have synergic actions together targeting common downstream signaling pathways. With this concern, among these common target genes, we identified that CXCL8 and SOX4, which expression levels were commonly up-regulated in the recurrent HCCs (RER UP, Figure 6D). The down-regulation of CXCL8 and $S O X 4$ expression in the knockdown cells for $G O L G B 1$ or $S F 3 B 3$ were further validated by qRT-PCR (Figure 6E), supporting that $C X C L 8$ and $S O X 4$ are the downstream targets of $G O L G B 1$ and $S F 3 B 3$. Indeed, previous studies have established well that the CXCL8 (IL-8) and SOX4 can promote cancer development and progression $[25$, 26]. In addition, we could observe positive correlations of the expression levels of $G O L G B 1$ or $S F 3 B 3$ with the expression levels of $C X C L 8$ and $S O X 4$ in the liver cancer data of TCGA, implying the potential connection between them (Supplementary Figure 5). Taken together, we suggest that the mutations of $G O L G B 1$ and $S F 3 B 3$ act to attain an aggressive phenotype in the recurrent $\mathrm{HCC}$, and which might be potentially through expression of $C X C L 8$ and SOX4.

\section{DISCUSSION}

In the present study, by performing RNA-Seq profiling of the paired primary and recurrent HCCs, we identified seven somatic mutations which were acquired by HCC recurrence. These included well-known cancer genes which mutations were previously found in primary HCCs. For example, TP53 mutation is one of the most frequent mutation in various cancer types including HCC. The mutated TP53 promotes aggressive phenotypes such as increased chromosome instability, metastasis, and poor prognosis of patients [27-29]. ARID1A is one of key components of chromatin remodeling complex. Frequent mutation of ARIDIA has been shown in $\mathrm{HCC}[14,30,31]$, provoking cancer progression and metastasis by epigenetic alteration. CCNL2 (Cyclin L2) is a member of the cyclin family, which was also reported to have tumor suppressor functions in HCC [32]. Although the sample size was limited in this study, re-identification of these well-known cancer mutants strongly support the reliability of our data and analytic strategy.

Of the recur-specific mutations, to obtain a proofof- concept, we demonstrated that the novel mutants of $G O L G B 1$ and $S F 3 B 3$ can promote oncogenic features. In fact, oncogenic functions of the $G O L G B 1$ and $S F 3 B 3$ were largely unknown. $G O L G B 1$, a golgi apparatus-associated

\section{A}

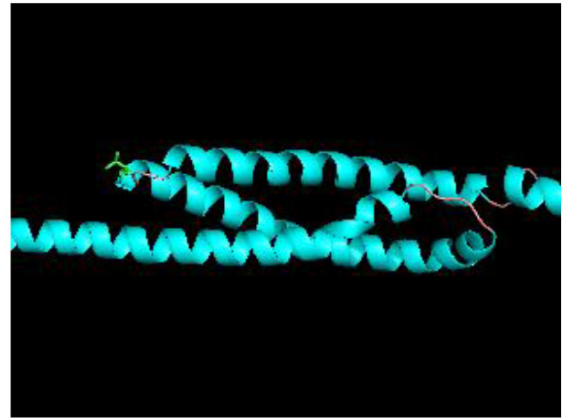

GOLGB1

B

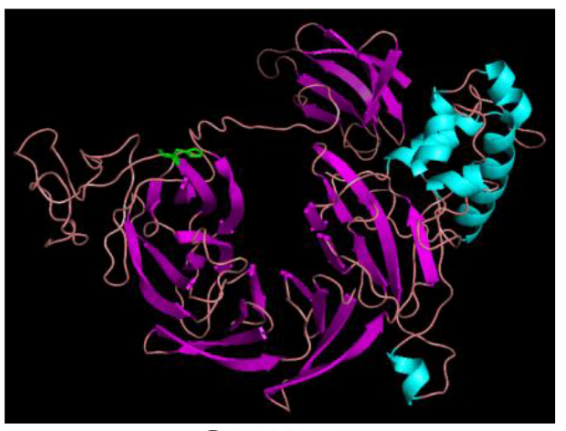

SF3B3

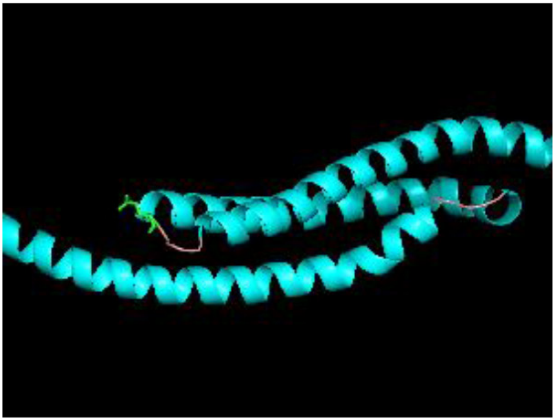

GOLGB1 (E2721V)

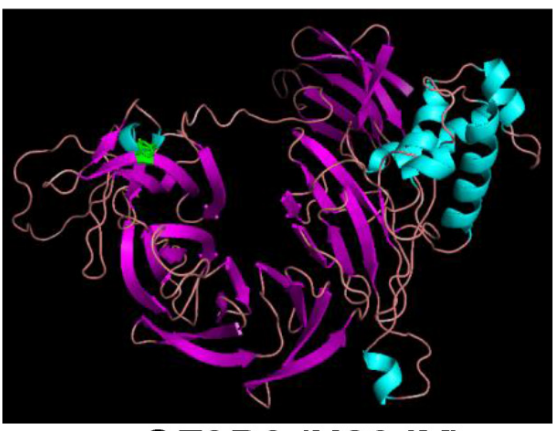

SF3B3 (H804Y)

Figure 5: Predicted protein structures for wild-type and mutant-type $G O L G B 1$ and $S F 3 B 3$. A, B. The predicted protein structures of the wild-type (left) and mutant-type (right) of GOLGB1 (A) and SF3B3 (B) and are shown. The mutation sites of GOLGB1 (E2721V) and SF3B3 (H804Y) are indicated with green color. 


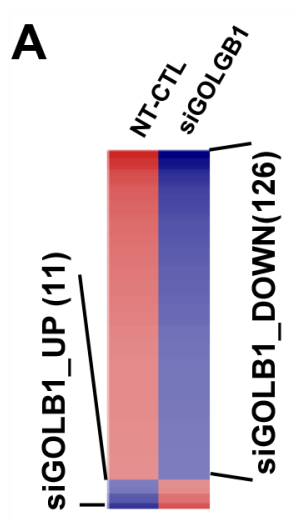

B

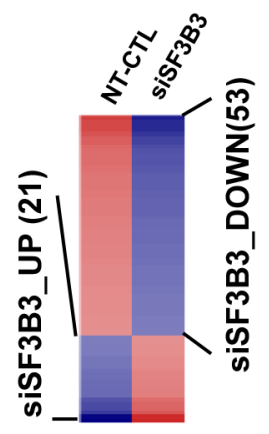

D sf3B3

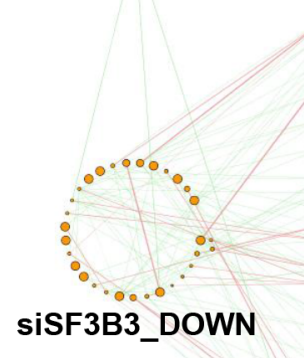

$\vdots$
$\vdots$
$\vdots$
$\vdots$
$\vdots$
$\vdots$
$\vdots$
$\vdots$
$\vdots$
$\vdots$
$\vdots$

SOX4 $\circ$ CXCL8

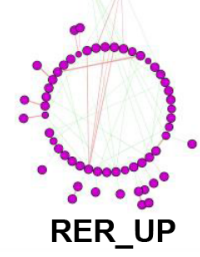

SIGOLGB1_DOWN

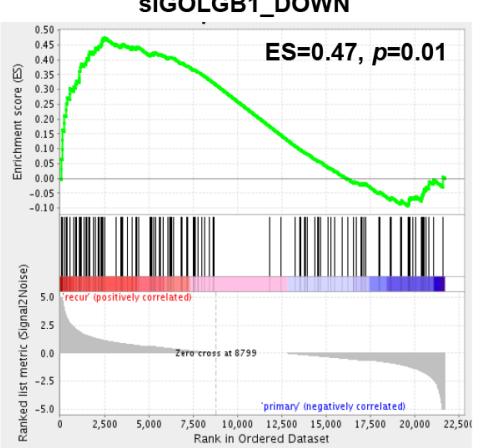

SISF3B3_DOWN

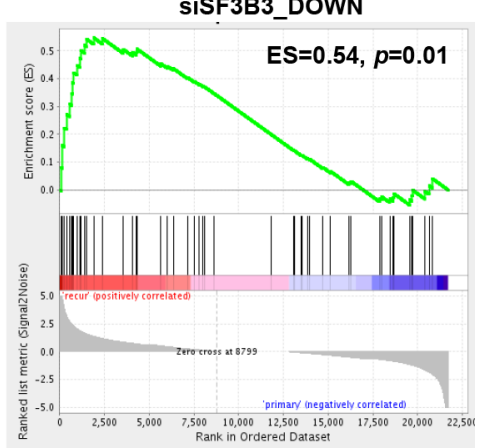

GOLGB1

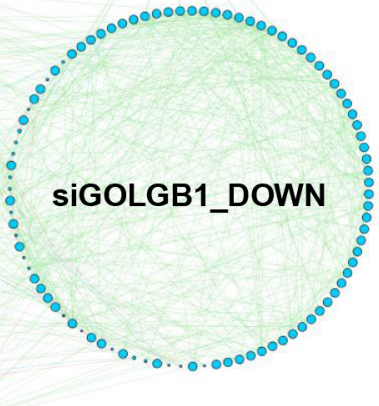

Genetic interactions

Pathway

Physical interactions

sigOLGB1_DOWN

SISF3B3_DOWN

RER_UP

Common (SF3B3 and GOLGB1)
C
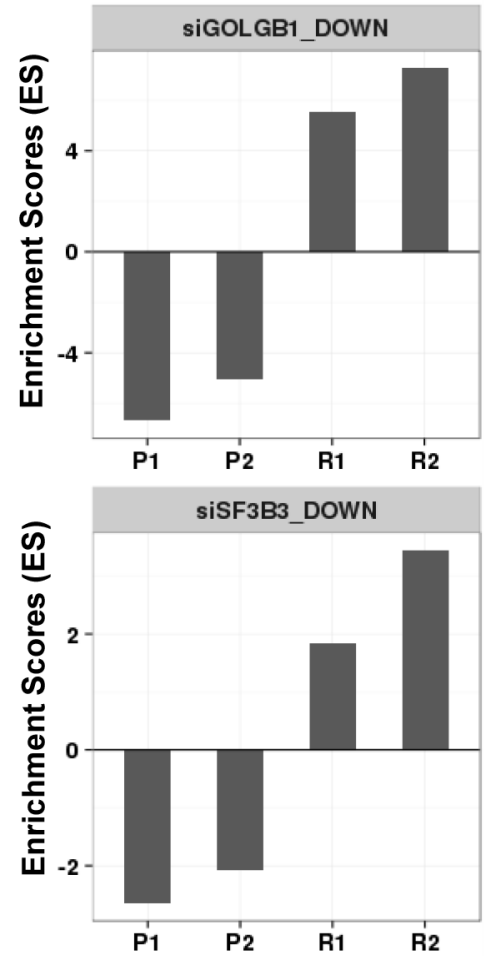

E
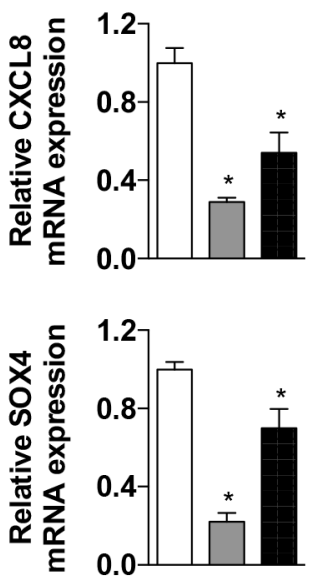

$\square$ NT-CTL $\square$ sigOLGB1

- siSF3B3

Figure 6: CXCL8 and SOX4 are potential downstream targets of the mutants of GOLGB1 and SF3B3. A. Heatmaps indicate the differentially expressed genes for the siRNA-mediated knockdown HepG2 cells for GOLGB1 (siGOLGB1, top) or SF3B3 (siSF3B3, bottom), respectively. B. The enriched expression of the gene sets of siGOLGB1_DOWN (top) and siSF3B3_DOWN (bottom) between the recurrent and the primary HCCs are shown, respectively. C. Bar plots indicate the enrichment scores of the siGOLGB1 DOWN (top) and siSF3B3_DOWN (bottom) gene signatures in individual HCC samples. D. Gene network analysis shows the gene sets of siSF3B3_DOWN ( $\mathrm{n}=53)$, siGOLGB1_DOWN $(\mathrm{n}=126)$, and the RER_UP $(\mathrm{n}=60)$ genes with different colors. Gene-to-gene interactions of physical (blue), genetic (green), and pathways (red) are shown with different colors. E. The expression levels of CXCL8 and SOX4 mRNAs are measured by qRT-PCR in the HepG2 cells transfected with NT-CTL (non-target control), GOLGB1, or SF3B3 siRNAs. Data are the mean \pm S.D. $(n=3) . * P<0.05$ with respective control. 
large transmembrane protein [33], has been reported to promote biogenesis and maintenance of compact golgi morphology, but its oncological roles has not been established yet. $S F 3 B 3$ is a protein for spliceosome assembly, which expression has been reported to associate with cancer cell growth [34] and prognosis of breast cancer patients $[35,36]$. We demonstrated that the overexpression of the $G O L G B 1$ or $S F 3 B 3$ promoted aggressive cancer progression such as cell proliferation, invasion, and migration reflecting aggressive behaviors of the recurrent HCC (see Figure 4). Moreover, the somatic mutations of these genes aggravated the aggressive phenotypes of HCC cells, implying their actions as activating mutations. Structural alteration of the mutant proteins was also predicted supporting their actionability (see Figure 5). Taken together, we suggest that the mutations of GOLGB1 or $S F 3 B 3$ can promote aggressive progression of $\mathrm{HCC}$.

In addition, we identified $C X C L 8$ and $S O X 4$ as potential common downstream targets of GOLGB1 and SF3B3 (see Figure 6D). CXCL8 (encoding $I L-8$ ) activates EGF and MAPK signaling cascades resulting in cancer progression and metastasis in diverse cancer types [37, 38]. SOX4 is an important regulator of EMT functioning in cancer progression [39]. Knockdown of SOX4 could suppress HCC cell migration, invasion, and intrahepatic metastasis [40]. Taken together, we suggest that the $C X C L 8$ and SOX4 are key down-stream effectors for the aggressive progression by the mutations GOLGB1 and/ or $S F 3 B 3$. However, the mechanistic relationships of GOLGB1 or SF3B3 with CXCL8 and/or SOX4 were not fully evaluated in this study, requiring further extended investigation.

In conclusion, by performing combined analyses of the mutation and transcriptome profiles and experimental evaluation, we successfully identified novel driver mutations and their potential target genes. Targeting GOLGB1 or $S F 3 B 3$ might have therapeutic or diagnostic advantages in precision management of HCC patients.

\section{MATERIALS AND METHODS}

\section{Patients and specimens}

Surgically resected HCC specimens of the paired primary and recurrent tumors from two $\mathrm{HCC}$ patients were obtained from the Ajou Human Bio-Resource Bank (AHBB), a member of the National Biobank of Korea, which is supported by the Ministry of Health and Welfare. Both the recurrent tumors occurred 14 months after surgical resection. The Institutional Review Board of Ajou University Hospital at Republic of Korea has approved this study, and waived the need for informed consent from donors.

\section{RNA-Seq profiling and data processing}

Total RNA was isolated using TRIzol® RNA Isolation Reagents (Life technologies, Carlsbad, CA), and the RNA integrity was confirmed by a bioanalyzer using an Agilent RNA 6000 Pico Kit (Agilent, Santa Clara, CA). The sequencing library for mRNA was constructed using TruSeq RNA sample preparation kit (illumina, San Diego, CA) according to manufacturer's instruction. Sequencing reaction was performed on an illumina HiSeq2000 for 100 -bp paired end reads ( 2 X 100) with coverage greater than 30 million reads per sample. The raw image data was transformed and stored in FASTQ format. The low quality sequence reads with less than 20 PHRED score were masked to ' $\mathrm{N}$ ' using 'fastq_masker' command of FASTX-toolkit (http://hannonlab.cshl.edu/fastx_toolkit/), then mapped to human reference genome (hg19) using Tophat [41] with default parameters. The PCR duplicates were removed by 'picard' MarkDuplicates (http://picard. sourceforge.net). The gene expression levels from RNASeq data were estimated by the log2-transformed FPKM values using Cufflinks [42].

\section{Variant calling from RNA-Seq data}

The RNA-Seq data were processed for variant calling. Local realignment of indel and normalization of base quality scores were performed using GATK IndelRealigner and Recalibrator, respectively [43]. The sequence variations were filtered by using GATK UnitiedGenotyper [43] with following conditions: (i) $\mathrm{MQ} 0<4$ and $\mathrm{MQ} 0 /\left(1.0^{*} \mathrm{DP}\right)>0.1$, (ii) $\mathrm{DP}<5$, (iii) $\mathrm{QUAL}<50$, (iv) $\mathrm{QD}<1.5$, where $\mathrm{MQ} 0$ indicate number of reads in which mapping quality zero, DP indicate read depth on variant position, QUAL is base call quality and QD is variant confidence by depth. In addition, the sequence variations with under 10 mutant read depth, known SNP (dbSNP138), or non-exonic variants were further filtered out, then the variants were annotated by using ANNOVAR software [44]. The identified mutants were validated using Sanger sequencing method.

\section{Microarray gene expression profiling}

Total RNA was amplified and purified using the Ambion Illumina RNA amplification kit (Ambion, Austin, TX) to yield biotinylated complementary DNA (cDNA) according to the manufacturer's instruction. Briefly, $550 \mathrm{ng}$ of total RNA was reverse-transcribed to cDNA using deoxythymidine oligomer primer and labeled with biotinylated deoxyribonucleotide triphosphate. Labeled cDNA samples were hybridized to human HT12 expression v.4 bead arrays, and the signal intensity was detected according to the manufacturer's instruction (Illumina, San Diego, CA). Raw data were processed by $\log 2$ transformation and quantile normalization.

\section{Gene ontology and gene set enrichment analyses}

Gene ontology (GO) analysis of the gene sets was performed using g:Profiler $\mathrm{R}$ package [45]. Statistical 
significance was determined with a cutoff of $\mathrm{P}<0.01$. To evaluate the aggressive phenotype of the recurrent HCC, we obtained 189 oncogenic signatures from $\mathrm{mSigDB}$ [46], and other cancer-related genes including stemness (i.e., ES1, nanog, sox2, oct4, NOS, myc1, myc2) [47], EMT [48], and cell cycle-related genes which have been reported previously.

Functional enrichment score for a gene signature was determined by applying Kolmogorov-Smirnov (KS) test. For each sample, directional P-values for the estimates D+ and D- were calculated by KS-test, and the enrichment score for a given signature was calculated as - $\log 10$ (P-value) as described previously [49]. In addition, gene set enrichment analysis between sample groups was performed using GSEA software [46]. All the statistical computation was performed using $\mathrm{R}$ software (http:// www.r-project.org).

\section{Cell culture and siRNA-mediated knockdown experiments}

Human HCC cell lines (i.e., HepG2, Huh7, Hep3B, SNU423, and PLC) obtained from the American Type Culture Collection (ATCC, Manassas, VA) were cultured in Dulbecco's modified Eagle's medium (DMEM) supplemented with 10\% fetal bovine serum (Gibco BRL, Grand Island, NY) and 100U penicillin/streptomycin at $37^{\circ} \mathrm{C}$ in a humidified $5 \% \mathrm{CO} 2$ incubator. Non-targeting control siRNA and siRNAs against human GOLGB1 and SF3B3 were purchased from Dharmacon Inc. (Lafayette, CO). Cells were transfected with each siRNA using Lipofectamine 3000 (Invitrogen, Carlsbad, CA) according to the manufacturer's instruction.

\section{Construction of expression vectors}

GOLGB1 and SF3B3 constructs were cloned by using In-fusion cloning method (Clontech, Mountain View, CA). Briefly, wild- and mutant-type clones for GOLGB1 or $S F 3 B 3$ were constructed by CloneAmp HiFi PCR premix (TAKARA, Tokyo, Japan) with specific primers (Supplementary Table 3). Large sized GOLGB1 was constructed by two bricks strategy using head (1 $5029 \mathrm{bp})$ and tail $(5030 \sim 9810 \mathrm{bp})$ bricks. The cDNA fragments were inserted into pcDNA3 vector using EcoRI and $\mathrm{XbaI}$. The PCR products of the mutants confirmed by Sanger DNA sequencing method.

\section{Cell proliferation and colony formation assays}

$2 \times 10^{3}$ cells per well were seeded in 96-well plates and incubated at $37^{\circ} \mathrm{C}$ in a humidified incubator containing $5 \% \mathrm{CO}_{2}$ overnight. After transfection for indicated time period, $5 \mathrm{mg} / \mathrm{mL}$ MTT solution (Amresco, Cleveland, $\mathrm{OH}$ ) was added to each well and incubated for $2 \mathrm{~h}$. The blue crystalline precipitate in each well was dissolved in 150 $\mu l$ per well DMSO, and the visible absorbance at $550 \mathrm{~nm}$ of each well was quantified using a microplate reader. All the experiments were performed in triplicate. For colony formation assay, cells were transfected with the constructs of mock control, and wild- or mutant-types of GOLGB1 or $S F 3 B 3$ for $48 \mathrm{~h}$, respectively. Then, 500 cells/well were seeded in the 6 -well plates for 14 days. The colonies were washed 2 times with phosphate-buffered saline (PBS), fixed with $3.7 \%$ Paraformaldehyde, and stained with $1 \%$ crystal violet solution in distilled water.

\section{Cell migration and invasion assays}

Cell migration and invasion assays were performed in 8- $\mu \mathrm{m}$-pore Transwells (6.5 mm; Costar, Corning, NY) with the Transwell filters of uncoated (for migration) or recoated (for invasion) with matrigel (100 $\mu$, diluted 1:10 in PBS for 1h, BD Biosciences, Bedford, MA), respectively. After rinsing the filters with PBS, the cells were plated and incubated for indicated time periods at $37^{\circ} \mathrm{C}, 5 \% \mathrm{CO} 2$. Non-invaded or migrated cells in the upper chamber were removed with a cotton swab. The invaded or migrated cells through the filter were washed with PBS, fixed with $3.7 \%$ formalin, and stained with $0.1 \%$ crystal violet for 1 $\mathrm{h}$. The number of invaded or migrated cells was counted under a light microscope.

\section{Quantitative real time-PCR (qRT-PCR)}

Total RNA was extracted from cells using the RNAiso plus (Takara, Tokyo, Japan). cDNA was synthesized from $2 \mu \mathrm{g}$ of total RNA using PrimeScript RT reagent Kit (Perfect Real Time) (Takara, Tokyo, Japan). Quantitation of the gene expression levels were performed by a CF96TM Optics Module using IQ SYBR Super Mix (Bio-Rad, Richmond, CA) with the specific primers (Supplementary Table 3). All reactions were triplicated, and the $2^{-\Delta \Delta} \mathrm{Ct}$ values were used for quantification.

\section{Western blotting}

Cells were washed twice with PBS and lysed with RIPA lysis buffer containing protease and phosphatase inhibitors at $4^{\circ} \mathrm{C}$ for $30 \mathrm{~min} .20 \mu \mathrm{g}$ of total protein was loaded onto $8 \%$ SDS-polyacrylamide gel electrophoresis (PAGE) and transferred onto nitrocellulose membranes (Bio-Rad). Membranes were blocked for $1 \mathrm{~h}$ in $0.2 \%$ I-Block $^{\mathrm{TM}}$ (Applied Biosysms) in TBST and then incubated for $1 \mathrm{~h}$ at room temperature or at $4^{\circ} \mathrm{C}$ overnight with primary antibody diluted in TBST containing $0.2 \%$ I-Block $^{\mathrm{TM}}$. The primary antibodies for anti-GOLGB1 (R\&D Systems, Minneapolis, MN) and anti-SF3B3 (Santa Cruz Biotechnology, Dallas, TX) were used. After three washes with TBST, the blots were incubated for 1 $\mathrm{h}$ with horseradish peroxidase-conjugated secondary antimouse (AbFrontier, Seoul, Korea) or anti-sheep (Abcam, 
Cambridge, MA) antibodies. The immunoblots were visualized by EzWestLumi (Atto, Tokyo, Japan).

\section{Protein structure analysis}

Protein structures of wild- and mutant-types of GOLGB1 or $S F 3 B 3$ were predicted using PSIPRED [50] with default parameters. The best scored protein model was selected, and its 3D structure was visualized using PyMOL (http://www.pymol.org).

\section{Abbreviations}

HCC, hepatocellular carcinoma; EMT, epithelial-tomesenchymal transition; FPKM, Fragments Per Kilobase Million; GO, Gene ontology. KS, Kolmogorov-Smirnov; RER, reprogrammed expression by recurrence; ES, enrichment score; TCGA, The Cancer Genome Atlas; DEG, differentially expressed gene. IGV, Integrated Genome Viewer.

\section{CONFLICTS OF INTEREST}

The authors declare no conflicts of interest.

\section{FUNDING}

This work was supported by grants from the Korea Healthcare Technology R\&D Project, Ministry of Health \& Welfare (HI14C3395 and HI15C1551) and from the National Research Foundation of Korea (NRF) funded by the Korea government (MSIP) (NRF2012R1A5A2048183).

\section{REFERENCES}

1. Jemal A, Bray F, Center MM, Ferlay J, Ward E, Forman D. Global cancer statistics. CA Cancer J Clin. 2011; 61:69-90.

2. Aravalli RN, Steer CJ, Cressman EN. Molecular mechanisms of hepatocellular carcinoma. Hepatology. 2008; 48:2047-2063.

3. Llovet JM, Schwartz M, Mazzaferro V. Resection and liver transplantation for hepatocellular carcinoma. Semin Liver Dis. 2005; 25:181-200.

4. Ramaswamy S, Ross KN, Lander ES, Golub TR. A molecular signature of metastasis in primary solid tumors. Nat Genet. 2003; 33:49-54.

5. Brodsky AS, Fischer A, Miller DH, Vang S, MacLaughlan S, Wu HT, Yu J, Steinhoff M, Collins C, Smith PJ, Raphael BJ, Brard L. Expression profiling of primary and metastatic ovarian tumors reveals differences indicative of aggressive disease. PLoS One. 2014; 9:e94476.

6. Woo HG, Park ES, Cheon JH, Kim JH, Lee JS, Park BJ, Kim W, Park SC, Chung YJ, Kim BG, Yoon JH, Lee $\mathrm{HS}$, Kim CY, et al. Gene expression-based recurrence prediction of hepatitis B virus-related human hepatocellular carcinoma. Clin Cancer Res. 2008; 14:2056-2064.

7. Kim JH, Sohn BH, Lee HS, Kim SB, Yoo JE, Park YY, Jeong W, Lee SS, Park ES, Kaseb A, Kim BH, Kim $\mathrm{WB}$, Yeon JE, et al. Genomic predictors for recurrence patterns of hepatocellular carcinoma: model derivation and validation. PLoS medicine. 2014; 11:e1001770.

8. Roessler S, Jia HL, Budhu A, Forgues M, Ye QH, Lee JS, Thorgeirsson SS, Sun Z, Tang ZY, Qin LX, Wang XW. A unique metastasis gene signature enables prediction of tumor relapse in early-stage hepatocellular carcinoma patients. Cancer Res. 2010; 70:10202-10212.

9. Guichard C, Amaddeo G, Imbeaud S, Ladeiro Y, Pelletier L, Maad IB, Calderaro J, Bioulac-Sage P, Letexier M, Degos F, Clement B, Balabaud C, Chevet E, et al. Integrated analysis of somatic mutations and focal copy-number changes identifies key genes and pathways in hepatocellular carcinoma. Nat Genet. 2012; 44:694-698.

10. Totoki Y, Tatsuno K, Covington KR, Ueda H, Creighton CJ, Kato M, Tsuji S, Donehower LA, Slagle BL, Nakamura H, Yamamoto S, Shinbrot E, Hama N, et al. Trans-ancestry mutational landscape of hepatocellular carcinoma genomes. Nat Genet. 2014; 46:1267-1273.

11. Schulze K, Imbeaud S, Letouze E, Alexandrov LB, Calderaro J, Rebouissou S, Couchy G, Meiller C, Shinde J, Soysouvanh F, Calatayud AL, Pinyol R, Pelletier L, et al. Exome sequencing of hepatocellular carcinomas identifies new mutational signatures and potential therapeutic targets. Nature genetics. 2015; 47:505-511.

12. Totoki Y, Tatsuno K, Yamamoto S, Arai Y, Hosoda F, Ishikawa S, Tsutsumi S, Sonoda K, Totsuka H, Shirakihara T, Sakamoto H, Wang L, Ojima H, et al. High-resolution characterization of a hepatocellular carcinoma genome. Nat Genet. 2011; 43:464-469.

13. Woo HG, Kim SS, Cho H, Kwon SM, Cho HJ, Ahn SJ, Park ES, Lee JS, Cho SW, Cheong JY. Profiling of exome mutations associated with progression of HBV-related hepatocellular carcinoma. PLoS One. 2014; 9:e115152.

14. Huang J, Deng Q, Wang Q, Li KY, Dai JH, Li N, Zhu ZD, Zhou B, Liu XY, Liu RF, Fei QL, Chen H, Cai B, Xiao HS, Qin LX, Han ZG. Exome sequencing of hepatitis B virus-associated hepatocellular carcinoma. Nat Genet. 2012; 44:1117-1121.

15. Kim J, Lee IH, Cho HJ, Park CK, Jung YS, Kim Y, Nam SH, Kim BS, Johnson MD, Kong DS, Seol HJ, Lee JI, Joo KM, et al. Spatiotemporal Evolution of the Primary Glioblastoma Genome. Cancer Cell. 2015; 28:318-328.

16. Ouyang L, Lee J, Park CK, Mao M, Shi Y, Gong Z, Zheng H, Li Y, Zhao Y, Wang G, Fu H, Kim J, Lim HY. Wholegenome sequencing of matched primary and metastatic hepatocellular carcinomas. BMC Med Genomics. 2014; 7:2.

17. Eleveld TF, Oldridge DA, Bernard V, Koster J, Daage LC, Diskin SJ, Schild L, Bentahar NB, Bellini A, Chicard M, Lapouble E, Combaret V, Legoix-Ne P, et al. Relapsed 
neuroblastomas show frequent RAS-MAPK pathway mutations. Nat Genet. 2015; 47:864-871.

18. Gerlinger M, Rowan AJ, Horswell S, Larkin J, Endesfelder D, Gronroos E, Martinez P, Matthews N, Stewart A, Tarpey P, Varela I, Phillimore B, Begum S, et al. Intratumor heterogeneity and branched evolution revealed by multiregion sequencing. N Engl J Med. 2012; 366:883-892.

19. Lee TK, Castilho A, Cheung VC, Tang KH, Ma S, Ng IO. $\mathrm{CD} 24(+)$ liver tumor-initiating cells drive self-renewal and tumor initiation through STAT3-mediated NANOG regulation. Cell stem cell. 2011; 9:50-63.

20. Qin G, Luo M, Chen J, Dang Y, Chen G, Li L, Zeng J, Lu Y, Yang J. Reciprocal activation between MMP-8 and TGF-beta1 stimulates EMT and malignant progression of hepatocellular carcinoma. Cancer Lett. 2016; 374:85-95.

21. Gao Q, Zhao YJ, Wang XY, Qiu SJ, Shi YH, Sun J, Yi Y, Shi JY, Shi GM, Ding ZB, Xiao YS, Zhao ZH, Zhou J, He XH, Fan J. CXCR6 upregulation contributes to a proinflammatory tumor microenvironment that drives metastasis and poor patient outcomes in hepatocellular carcinoma. Cancer Res. 2012; 72:3546-3556.

22. Huang W, Chen Z, Zhang L, Tian D, Wang D, Fan D, Wu $\mathrm{K}$, Xia L. Interleukin-8 Induces Expression of FOXC1 to Promote Transactivation of CXCR1 and CCL2 in Hepatocellular Carcinoma Cell Lines and Formation of Metastases in Mice. Gastroenterology. 2015; 149:10531067 e1014.

23. Chen Z, Lu X, Wang Z, Jin G, Wang Q, Chen D, Chen T, Li J, Fan J, Cong W, Gao Q, He X. Co-expression of PKM2 and TRIM35 predicts survival and recurrence in hepatocellular carcinoma. Oncotarget. 2015; 6:2538-2548. doi: 10.18632/oncotarget.2991.

24. Montojo J, Zuberi K, Rodriguez H, Kazi F, Wright G, Donaldson SL, Morris Q, Bader GD. GeneMANIA Cytoscape plugin: fast gene function predictions on the desktop. Bioinformatics. 2010; 26:2927-2928.

25. Ning Y, Manegold PC, Hong YK, Zhang W, Pohl A, Lurje G, Winder T, Yang D, LaBonte MJ, Wilson PM, Ladner RD, Lenz HJ. Interleukin-8 is associated with proliferation, migration, angiogenesis and chemosensitivity in vitro and in vivo in colon cancer cell line models. Int J Cancer. 2011; 128:2038-2049.

26. Zhou Y, Wang X, Huang Y, Chen Y, Zhao G, Yao Q, Jin C, Liu X, Li G. Down-regulated SOX4 expression suppresses cell proliferation, metastasis and induces apoptosis in Xuanwei female lung cancer patients. J Cell Biochem. 2015; 116:1007-1018.

27. Powell E, Piwnica-Worms D, Piwnica-Worms H. Contribution of p53 to metastasis. Cancer Discov. 2014; 4:405-414.

28. Woo HG, Wang XW, Budhu A, Kim YH, Kwon SM, Tang ZY, Sun Z, Harris CC, Thorgeirsson SS. Association of TP53 mutations with stem cell-like gene expression and survival of patients with hepatocellular carcinoma. Gastroenterology. 2011; 140:1063-1070.
29. Hanel W, Moll UM. Links between mutant p53 and genomic instability. J Cell Biochem. 2012; 113:433-439.

30. Fujimoto A, Totoki Y, Abe T, Boroevich KA, Hosoda F, Nguyen HH, Aoki M, Hosono N, Kubo M, Miya F, Arai Y, Takahashi H, Shirakihara T, et al. Whole-genome sequencing of liver cancers identifies etiological influences on mutation patterns and recurrent mutations in chromatin regulators. Nat Genet. 2012; 44:760-764.

31. Cleary SP, Jeck WR, Zhao X, Chen K, Selitsky SR, Savich GL, Tan TX, Wu MC, Getz G, Lawrence MS, Parker JS, Li J, Powers S, et al. Identification of driver genes in hepatocellular carcinoma by exome sequencing. Hepatology. 2013; 58:1693-1702.

32. Yang L, Li N, Wang C, Yu Y, Yuan L, Zhang M, Cao X. Cyclin L2, a novel RNA polymerase II-associated cyclin, is involved in pre-mRNA splicing and induces apoptosis of human hepatocellular carcinoma cells. J Biol Chem. 2004; 279:11639-11648.

33. Linstedt AD, Hauri HP. Giantin, a novel conserved Golgi membrane protein containing a cytoplasmic domain of at least $350 \mathrm{kDa}$. Mol Biol Cell. 1993; 4:679-693.

34. Bonnal S, Vigevani L, Valcarcel J. The spliceosome as a target of novel antitumour drugs. Nature reviews Drug discovery. 2012; 11:847-859.

35. Gokmen-Polar Y, Neelamraju Y, Goswami CP, Gu X, Nallamothu G, Janga SC, Badve S. Expression levels of SF3B3 correlate with prognosis and endocrine resistance in estrogen receptor-positive breast cancer. Modern pathology. 2015; 28:677-685.

36. Srihari S, Kalimutho M, Lal S, Singla J, Patel D, Simpson PT, Khanna KK, Ragan MA. Understanding the functional impact of copy number alterations in breast cancer using a network modeling approach. Molecular bioSystems. 2016; 12:963-972.

37. Inoue K, Slaton JW, Kim SJ, Perrotte P, Eve BY, Bar-Eli M, Radinsky R, Dinney CP. Interleukin 8 expression regulates tumorigenicity and metastasis in human bladder cancer. Cancer Res. 2000; 60:2290-2299.

38. Luppi F, Longo AM, de Boer WI, Rabe KF, Hiemstra PS. Interleukin-8 stimulates cell proliferation in non-small cell lung cancer through epidermal growth factor receptor transactivation. Lung Cancer. 2007; 56:25-33.

39. Tiwari N, Tiwari VK, Waldmeier L, Balwierz PJ, Arnold P, Pachkov M, Meyer-Schaller N, Schubeler D, van Nimwegen E, Christofori G. Sox 4 is a master regulator of epithelial-mesenchymal transition by controlling Ezh2 expression and epigenetic reprogramming. Cancer Cell. 2013; 23:768-783.

40. Liao YL, Sun YM, Chau GY, Chau YP, Lai TC, Wang JL, Horng JT, Hsiao M, Tsou AP. Identification of SOX4 target genes using phylogenetic footprinting-based prediction from expression microarrays suggests that overexpression of SOX4 potentiates metastasis in hepatocellular carcinoma. Oncogene. 2008; 27:5578-5589. 
41. Trapnell C, Pachter L, Salzberg SL. TopHat: discovering splice junctions with RNA-Seq. Bioinformatics. 2009; 25:1105-1111.

42. Trapnell C, Williams BA, Pertea G, Mortazavi A, Kwan G, van Baren MJ, Salzberg SL, Wold BJ, Pachter L. Transcript assembly and quantification by RNA-Seq reveals unannotated transcripts and isoform switching during cell differentiation. Nat Biotechnol. 2010; 28:511-515.

43. DePristo MA, Banks E, Poplin R, Garimella KV, Maguire JR, Hartl C, Philippakis AA, del Angel G, Rivas MA, Hanna M, McKenna A, Fennell TJ, Kernytsky AM, et al. A framework for variation discovery and genotyping using next-generation DNA sequencing data. Nat Genet. 2011; 43:491-498.

44. Wang K, Li M, Hakonarson H. ANNOVAR: functional annotation of genetic variants from high-throughput sequencing data. Nucleic Acids Res. 2010; 38:e164.

45. Reimand J, Arak T, Adler P, Kolberg L, Reisberg S, Peterson H, Vilo J. g:Profiler-a web server for functional interpretation of gene lists (2016 update). Nucleic Acids Res. 2016; 44:W83-89.

46. Subramanian A, Tamayo P, Mootha VK, Mukherjee S, Ebert BL, Gillette MA, Paulovich A, Pomeroy SL, Golub
TR, Lander ES, Mesirov JP. Gene set enrichment analysis: a knowledge-based approach for interpreting genomewide expression profiles. Proc Natl Acad Sci U S A. 2005; 102:15545-15550.

47. Ben-Porath I, Thomson MW, Carey VJ, Ge R, Bell GW, Regev A, Weinberg RA. An embryonic stem cell-like gene expression signature in poorly differentiated aggressive human tumors. Nat Genet. 2008; 40:499-507.

48. Taube JH, Herschkowitz JI, Komurov K, Zhou AY, Gupta S, Yang J, Hartwell K, Onder TT, Gupta PB, Evans KW, Hollier BG, Ram PT, Lander ES, Rosen JM, Weinberg RA, Mani SA. Core epithelial-to-mesenchymal transition interactome gene-expression signature is associated with claudin-low and metaplastic breast cancer subtypes. Proc Natl Acad Sci U S A. 2010; 107:15449-15454.

49. Woo HG, Lee JH, Yoon JH, Kim CY, Lee HS, Jang JJ, Yi NJ, Suh KS, Lee KU, Park ES, Thorgeirsson SS, Kim YJ. Identification of a cholangiocarcinoma-like gene expression trait in hepatocellular carcinoma. Cancer research. 2010; 70:3034-3041.

50. Buchan DW, Minneci F, Nugent TC, Bryson K, Jones DT. Scalable web services for the PSIPRED Protein Analysis Workbench. Nucleic Acids Res. 2013; 41:W349-357. 